\title{
Using Search Engine Count Estimates as Indicators of Academic Impact: A Web-based Replication of Haggbloom et al.'s (2002) Study
}

\author{
Matthias Spörrle ${ }^{1, *}$ and Andranik Tumasjan ${ }^{2}$ \\ ${ }^{1}$ University of Applied Management (UAM), Am Bahnhof 2, D-85435 Erding, Germany \\ ${ }^{2}$ Technische Universität München, Leopoldstr. 139, D-80804 München, Germany
}

\begin{abstract}
Using a complex set of quantitative and qualitative indicators of scientific importance, Haggbloom et al. [1] compiled a ranking of the most eminent psychologists of the 20th century. The present study set out to replicate this rankordered list using simple search engine count estimates (SECEs) obtained from three popular internet search engines. In line with our expectations, our results revealed a small, but significant relationship between SECEs and the existing offline ranking when the query specified the scientist's field of research (i.e., psychology). Our results imply that SECEs may be considered easy to apply indicators of a researcher's impact.
\end{abstract}

Keywords: Scientometrics, internet, search engines, impact, scientific eminence, psychologist.

\section{INTRODUCTION}

The Internet is not only a powerful means of communication and information distribution, but also constitutes a significant resource for scientific analysis. Especially in the social sciences, web-based research has led to a variety of new data collection methods that make use of the novel technological features and possibilities of the Internet [2-4], analyze already existing content of web pages [5-7]; or use a combination of both [8]. For instance, Norenzayan et al. [6] reasoned that the popularity of certain folk tales would be reflected by the number of their mentions on web pages. Accordingly, the authors used page counts of the search engine Google as an indicator of the pervasiveness of these folk tales. As expected, when surveying the folk tales' pervasiveness offline (i.e., assessing participants' familiarity with these folk tales in a paper-and-pencil survey) the authors found high convergence of online and offline indicators of folktale popularity. Such findings indicate that the popularity of certain ideas in the "real world" might be also reflected by frequency indicators based on internet content [see also 9].

Applying this argument to the realm of scientific impact (e.g., the academic popularity of certain researchers' ideas) it can be plausibly assumed that the influence of scholars may also be validly estimated by examining internet content. Accordingly, a relatively new field of research measuring scientific impact using Internet indicators has emerged over the past years [10-17]. Webometric research traditionally used hyperlinks (analogously to offline citation bibliometrics) as indicators of scientific impact [cf. 18, 19], but recently also started to develop and apply more innovative measures of scientific eminence (such as the frequency of visits or

\footnotetext{
*Address correspondence to this author at the University of Applied Management (UAM), Am Bahnhof 2, D-85435 Erding, Germany;

Tel: +49 (8122) 955948 0; Fax: +49 (8122) 955948 49;

E-mail: matthias.spoerrle@fham.de
}

downloads from academic sites, the number of files in academic sites' repositories or the number of pages of an academic site indexed by search engines; cf. [20]). For instance, Bagrow and ben-Avraham [21] examined the fame distribution of scientists and other groups (e.g., runners, programmers, actors) finding that the underlying Google data do not always allow for clear conclusions regarding the nature of the distribution (e.g., power-law function).

Consistent with these recent developments [22-24], Janetzko [25] has recently enhanced our methodological understanding of web-based research by examining the objectivity, reliability, and validity of search engine count estimates (SECEs; i.e., the number of results or "hits" one receives upon entering a search term in an internet search engine) for a number of concepts. Overall his findings demonstrate that these three classical goodness criteria can be considered satisfactory to good for SECEs. The present article builds on the previous work by applying the method of SECEs to the measurement of the scientific eminence of psychologists as reflected on the internet. In line with previous research, we argue that the frequency of a scientist's name on the internet (measured by search engine page counts) should to some extent reflect her/his scientific impact captured by traditional indicators (e.g., reputation among peer scientists). In order to test this assumption, we apply the SECEs method to the measurement of scientific eminence in our own discipline (i.e., psychology) as a first step. In particular, in order to validate our results against complex traditional indicators of scientific impact, the present study aims at replicating a rank-ordered list of the most eminent psychologists of the 20th century developed by Haggbloom et al. [1]. In the following, we describe the ranking procedure as well as the indicators of scientific eminence used in Haggbloom et al.'s [1] study.

Retrospectively appraising notable contributions to the field of psychology, Haggbloom et al. [1] compiled a list of the 100 most eminent psychologists of the 20th century (al- 
though they report only the first 99). The authors used three quantitative and three qualitative indicators of eminence to create their rank-ordered list. The quantitative indicators comprise the following measures. First, a journal citation frequency indicator was used adding citation frequencies across four previously published citation lists. Second, an introductory textbook citation frequency list was constructed using three lists. Third, a survey was mailed to the members of the American Psychological Association (APA) asking them to name the "greatest psychologists of the 20th century" in their opinion. The authors' qualitative indicators consisted of the following dichotomous variables: (1) election to the National Academy of Sciences, (2) recipient of the APA Distinguished Scientific Contributions Award or elected APA president (as of 1999), or both, and (3) existence of the scientist's surname as an eponym (e.g., Kelley's attribution theory). All six indicators were then used to calculate an elaborate composite score for each psychologist resulting in the final rank-ordered list [1]. Although it can be argued that this list is biased toward American psychologists (as Haggbloom et al. point out themselves), we argue that it is valid to use this list as reference data for our analyses for three reasons. First, even though the list might be biased toward American researchers, it is by no means restricted to them. For instance, just to name a few, Jean Piaget, Sigmund Freud, Kurt Lewin, Ivan Pavlov, Walter Mischel, John Bowlby, Konrad Lorenz, Alfred Adler, and Lev Vygotsky can be found on the list, too (cf. Appendix).

Second, science in general and psychological science in particular, is largely dominated by American researchers, especially in the second half of the 20th century (even in today's scientific market with increased competition, especially from Asian countries, North America still produces more than $30 \%$ of the world's scientific publications) [cf. 26, 27]. Thus, Haggbloom et al.'s [1] list can be considered to represent a substantial share of the worldwide scientific psychological community, since a large proportion of psychological science output in the 20th century was produced by scientists from North American institutions.

Third, we argue that it is implausible to assume that the basic relationship between SECEs and scientific impact as measured by offline indicators would change if one used a rank-ordered list of psychologists from other countries or if one used other languages. We posit that the more impact a scientist has on the internet, the more eminent he/she will be as measured by other indicators, independent of country of origin and language. Thus, this basic association should be robust no matter whether one examines American psychologists and an English language query or Chinese psychologists and a Chinese language query (if anything, examining scientists from American institutions should be relatively more valid than other approaches, as English is the most important language in science [28] as well as on the internet [29]).

The goal of the present study was to replicate Haggbloom et al.'s [1] rank-ordered list that was compiled based on complex offline resources by simply applying SECEs as indicators of scientific eminence. By doing so we provide first evidence that SECEs can be used as a simple indicator of scientific relevance.

\section{METHOD}

\section{Search Engines}

We used three search engines to correct for possible biases and establish a more reliable indicator of internet frequency. The web services were chosen to meet two criteria: (1) Frequent usage within the Internet community and (2) relatively high levels of independence from each other thus reducing the overlap of the search results. Three search engines that met these criteria were selected (Janetzko, 2008): Google (www.google.com), Yahoo (www.yahoo.com), and $M S N$ (www.msn.com).

\section{Search Queries}

Three different types of internet search engine queries for the $N=99$ psychologists' names were used: (1) first name and surname (e.g., Albert Bandura), (2) first name and surname and the word "psychology" (e.g., Albert Bandura psychology), and (3) first name and surname and the word "psychologist" (e.g., Albert Bandura psychologist). Note that the search queries including only the name might very well obtain a large number of web pages which have nothing to do with the psychologist of that name (especially in cases, in which the psychologist has a quite common name, e.g., George Miller). Adding the words "psychology" or "psychologist" was assumed to increase the probability that the internet pages retrieved will actually refer to the famous psychologist.

The queries were entered without further restrictions (e.g., no phrase search) to ensure that all websites on which the first name, the surname, and "psychology" or "psychologist" are mentioned together (no matter in which conjunction) are taken into account. Otherwise results would have been limited to pages where the strings "first name surname psychology/psychologist" are mentioned together in form of coherent phrases.

\section{Procedure}

The query was done automatically by using a self-written internet spider. All queries were submitted at five times between April and May 2007. Even though this period of time is a few years after the data collection of our reference work of Haggbloom et al. [1] we think that - given the time it takes to build or abolish scientific reputation - our data should still to some extent reflect their ranking.

\section{RESULTS}

The absolute frequencies (i.e., the SECEs) obtained by the internet spider were ranked in order to correct for extreme values and non-normal distribution as well as to allow for the computation of parametric correlation coefficients (for details on the application of parametric correlation coefficients on rank transformed data see [30]). Overall, the three internet search engines' rankings revealed high convergence across the three types of search query. All computed correlations between the search engines' rankings for each type of query ranged between $r=.92$ and $r=.98$. Thus, in line with existing evidence all three search engines produced similar rankings for the SECEs [cf. 25]. Moreover, the five meas- 
Table 1. Correlations Between Haggbloom et al.'s [1] Ranking and Rankings for the Three Types of SECEs for all Three Search Engines and Their Mean Averages

\begin{tabular}{|l|l|l|l|l|l|l|l|l|l|l|l|}
\hline Indicator & \multicolumn{3}{|l|}{ First Name + Surname } & \multicolumn{3}{l|}{ First Name + Surname + Psychology } & \multicolumn{2}{l|}{ First Name + Surname + Psychologist } \\
\hline & Google & MSN & Yahoo & $\begin{array}{l}\text { Mean } \\
\text { Ranking }\end{array}$ & Google & MSN & Yahoo & $\begin{array}{l}\text { Mean } \\
\text { Ranking }\end{array}$ & Google & MSN & Yahoo \\
$\begin{array}{l}\text { Mean } \\
\text { Ranking }\end{array}$ \\
\hline \hline $\begin{array}{l}\text { Haggbloom } \\
\text { et al.'s ranking }\end{array}$
\end{tabular}

$* p<.05$ (two-tailed).

${ }^{1}$ Haggbloom et al.'s [1] rank-ordered list of the 100 most eminent psychologists of the 20th century.

${ }^{2}$ Replicated SECEs-based rank-ordered list (averaged across three search engines) based on query of scientists' first name and surname (e.g., Albert Bandura).

${ }^{3}$ Replicated SECEs-based rank-ordered list (averaged across three search engines) based on query of scientists' first name and surname and the word "psychology" (e.g., Albert Bandura psychology).

${ }^{4}$ Replicated SECEs-based rank-ordered list (averaged across three search engines) based on query of scientists' first name and surname and the word "psychologist" (e.g., Albert Bandura psychologist).

urement replications revealed a highly reliable rank order for each of the three search engines (ICCs were between .98 and 1.00). Therefore all five measurements were mean averaged for each of the three search engines in order to form three overall internet rankings for the three types of search query.

Subsequently, we computed correlation coefficients between Haggbloom et al.'s [1] ranking and the rankings that resulted from the three types of query (see Appendix A for Haggbloom et al.'s ranking and Appendices B-D for all SECEs based rank-ordered lists). As can be seen from Table 1, simply querying for a scientist's name resulted in positive but non-significant correlation coefficients $(.10<r<.12)$. However, significant correlations in line with our expectations emerged when querying for a scientist's name in combination with his/her scientific discipline (i.e., psychology; $.18<r<.26, p<.05$ ) or his/her profession (i.e., psychologist; $.18<r<.29, p<.05)$. Hence, the present results indicate that our ranking procedure based on simple SECEs is reliable and that the resulting rank-ordered list is significantly associated with the respective offline criterion of scientific eminence (i.e., the ranking provided by Haggbloom et al.). Comparing the correlations between the three different kinds of search query indicates that specifying the field of research/profession increases the relationship between the SECEs ranking and Haggbloom et al.'s [1] offline ranking, thus indicating that the SECEs indicator's predictive validity can be improved when the scientist's field is also specified in the query.

Even though the correlations based on SECEs data which include the author's scientific field resulted in significant relationships with Haggbloom et al.'s [1] list, these correlations are of a small to moderate effect size at best [cf. 31]. Therefore, we performed an exploratory examination of the obtained rankings to find possible explanations for this comparatively weak association. Examining the ranking data clearly indicates that rare names are actually ranked remarkably accurately by the SECEs-based approach (e.g., the difference between the ranking of Haggbloom et al. and the internet ranking based on the name together with the word "psychology" for Hobart Mowrer and Herman Witkin was smaller than 5 ranks). In contrast, for names consisting of very frequent first names and surnames, relatively large discrepancies were observed. For instance, for James Gibson, Allen Edwards, John Dewey, and John Garcia the difference was larger than 70 ranks (in all of these cases the SECEsbased rank was substantially higher than the Haggbloom et al. indicator). In these four cases the first name as well as the surname is extremely common and sometimes even several well-known persons of the same name exist (e.g., within the English edition of Wikipedia there are currently [May 2011] more than fifteen entries on persons called James Gibson). Simply removing these four cases from the analysis resulted in a substantial increase of the mean ranking correlation with the offline indicator from $r=.20$, $p<.05$, to $r=.30, p<.005$. Thus, this analysis suggests that especially the common names lead to a decrease of the validity of the SECEs-based indicator.

\section{DISCUSSION}

This research aimed at investigating the use of search engine count estimates (SECEs) as indicators of scientific reputation by comparing the SECEs obtained from specific queries with a ranking from a highly sophisticated offline index of scientific eminence from the field of psychology [1].

Our results indicate that the rankings based on SECEs are positively and significantly associated with Haggbloom et al.'s [1] offline ranking. Additionally specifying the scientific field (i.e., psychology) or the profession (i.e., psychologist) of an author query both resulted in a considerably higher relationship than querying only the author's first name and surname. This finding indicates that webometrics research examining the impact of scientists might be well-advised to integrate general descriptors of the scientist's field in the search query in order to increase the validity of this approach.

Although we were able to detect significant positive correlations between the SECEs-based indicators and Haggbloom et al.'s [1] elaborate offline measure in line with our predictions, these relationships were small. We suggest two explanations for this result. First, our exploratory data analysis indicates that especially queries of common first names and surnames reduce the associations between the two indi- 
cators, since these common names generally receive very high frequencies (even when words such as "psychology" are included) independent from the scientific status of the researcher. Removing just a few cases with combinations of extremely common names resulted in substantial increases of the relationship between the online and the offline indicators. A second potential explanation for the relatively weak associations lies within the data itself. The 99 authors queried are all very influential psychologists. Given the thousands of psychologists working in academic settings - in 1972 the total membership of the APA, the largest organization of psychologists in the United States, was more than 35,000 [32] - our small sample can only be regarded as the very top section of psychological scientists. Therefore, compared to the total population of academic psychologists, the psychologists of our sample may very well be considered as being very close to each other in terms of their substantial scientific eminence. Keeping this potential ceiling effect in mind, the medium-sized correlations obtained in this study seem to be rather promising. Even when examining only this small group of only the highest ranking psychologists, simple and easily obtainable SECEs are significantly associated with the authors' scientific eminence.

\section{ACKNOWLEDGEMENT}

Preliminary analyses of these data were presented in a poster session at the $29^{\text {th }}$ International Congress of Psychology 2008, Berlin, Germany [see 33].

\section{APPENDIX}

\section{Comparison of Haggbloom et al.'s [1] ranking with the ranking results based on the three SECEs}

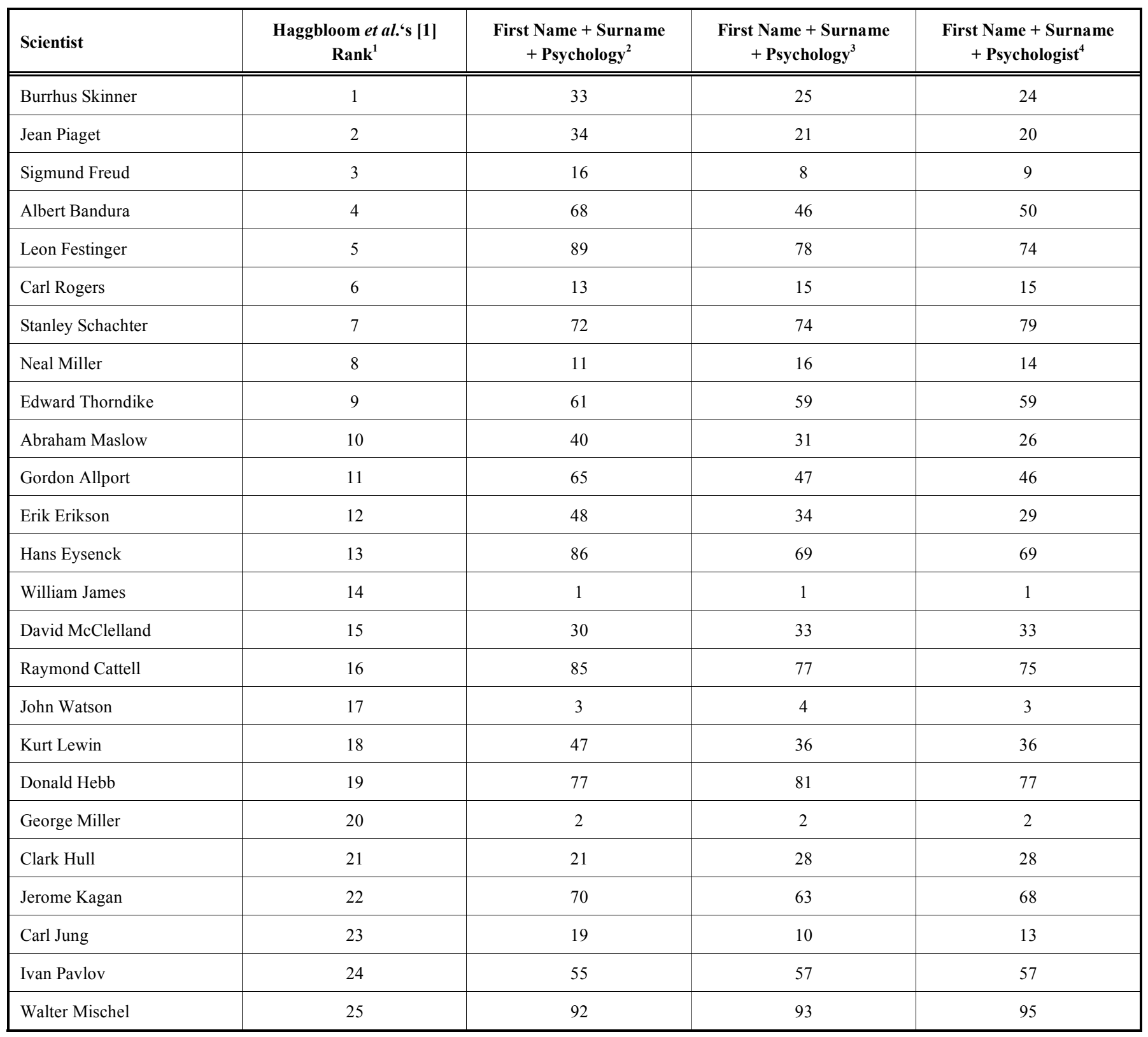


Appendix. Contd....

\begin{tabular}{|c|c|c|c|c|}
\hline Scientist & $\begin{array}{c}\text { Haggbloom et al.'s [1] } \\
\text { Rank }^{1}\end{array}$ & $\begin{array}{c}\text { First Name + Surname } \\
+ \text { Psychology }^{2}\end{array}$ & $\begin{array}{c}\text { First Name + Surname } \\
+ \text { Psychology }^{3}\end{array}$ & $\begin{array}{c}\text { First Name }+ \text { Surname } \\
+ \text { Psychologist }^{4}\end{array}$ \\
\hline Harry Harlow & 26 & 37 & 54 & 53 \\
\hline Joy Guilford & 27 & 63 & 52 & 44 \\
\hline Jerome Bruner & 28 & 58 & 44 & 45 \\
\hline Ernest Hilgard & 29 & 93 & 88 & 90 \\
\hline Lawrence Kohlberg & 30 & 67 & 56 & 54 \\
\hline Martin Seligman & 31 & 43 & 30 & 31 \\
\hline Ulric Neisser & 32 & 96 & 91 & 93 \\
\hline Donald Campbell & 33 & 9 & 13 & 11 \\
\hline Roger Brown & 34 & 4 & 5 & 5 \\
\hline Robert Zajonc & 35 & 88 & 87 & 87 \\
\hline Endel Tulving & 36 & 97 & 95 & 94 \\
\hline Herbert Simon & 37 & 15 & 14 & 16 \\
\hline Noam Chomsky & 38 & 14 & 17 & 19 \\
\hline Edward Jones & 39 & 5 & 3 & 4 \\
\hline Charles Osgood & 40 & 39 & 61 & 60 \\
\hline Solomon Asch & 41 & 79 & 80 & 78 \\
\hline Gordon Bower & 42 & 44 & 49 & 52 \\
\hline Harold Kelley & 43 & 26 & 18 & 17 \\
\hline Roger Sperry & 44 & 51 & 64 & 66 \\
\hline Edward Tolman & 45 & 69 & 76 & 76 \\
\hline Stanley Milgram & 46 & 62 & 42 & 40 \\
\hline Arthur Jensen & 47 & 22 & 26 & 25 \\
\hline Lee Cronbach & 48 & 78 & 55 & 51 \\
\hline John Bowlby & 49 & 59 & 40 & 41 \\
\hline Wolfgang Kohler & 50 & 52 & 73 & 81 \\
\hline David Wechsler & 51 & 45 & 43 & 43 \\
\hline Stanley Stevens & 52 & 17 & 22 & 21 \\
\hline Joseph Wolpe & 53 & 66 & 94 & 92 \\
\hline Donald Broadbent & 54 & 60 & 84 & 84 \\
\hline Roger Shepard & 55 & 32 & 37 & 37 \\
\hline Michael Posner & 56 & 25 & 29 & 32 \\
\hline Theodore Newcomb & 57 & 71 & 83 & 82 \\
\hline Elizabeth Loftus & 58 & 56 & 48 & 48 \\
\hline Paul Ekman & 59 & 46 & 45 & 47 \\
\hline Robert Sternberg & 60 & 36 & 27 & 30 \\
\hline Karl Lashley & 61 & 83 & 86 & 88 \\
\hline Kenneth Spence & 62 & 38 & 39 & 39 \\
\hline Morton Deutsch & 63 & 41 & 50 & 49 \\
\hline Julian Rotter & 64 & 87 & 97 & 97 \\
\hline
\end{tabular}


Appendix. Contd....

\begin{tabular}{|c|c|c|c|c|}
\hline Scientist & $\begin{array}{c}\text { Haggbloom et al. }{ }^{\prime} \mathrm{s}[1] \\
\text { Rank }^{1}\end{array}$ & $\begin{array}{c}\text { First Name + Surname } \\
+ \text { Psychology }^{2}\end{array}$ & $\begin{array}{c}\text { First Name + Surname } \\
+ \text { Psychology }^{3}\end{array}$ & $\begin{array}{c}\text { First Name + Surname } \\
+ \text { Psychologist }\end{array}$ \\
\hline Konrad Lorenz & 65 & 35 & 51 & 58 \\
\hline Benton Underwood & 66 & 53 & 90 & 89 \\
\hline Alfred Adler & 67 & 27 & 24 & 27 \\
\hline Eleanor Maccoby & 70 & 95 & 92 & 91 \\
\hline Robert Plomin & 71 & 90 & 85 & 85 \\
\hline Stanley Hall & 72 & 8 & 6 & 7 \\
\hline Leonard Berkowitz & 76 & 64 & 66 & 64 \\
\hline William Estes & 77 & 24 & 35 & 35 \\
\hline Eliot Aronson & 78 & 74 & 71 & 65 \\
\hline Irving Janis & 79 & 57 & 67 & 67 \\
\hline Richard Lazarus & 80 & 28 & 32 & 34 \\
\hline Gary Cannon & 81 & 18 & 19 & 18 \\
\hline Allen Edwards & 82 & 10 & 11 & 10 \\
\hline David Rumelhart & 88 & 84 & 72 & 80 \\
\hline Luis Thurston & 89 & 50 & 82 & 71 \\
\hline Margarete Washburn & 90 & 76 & 68 & 70 \\
\hline Robert Woodworth & 91 & 49 & 70 & 73 \\
\hline Edwin Boring & 92 & 54 & 62 & 63 \\
\hline John Dewey & 93 & 12 & 12 & 12 \\
\hline Amos Tversky & 94 & 80 & 60 & 61 \\
\hline Wilhelm Wundt & 95 & 73 & 53 & 55 \\
\hline Herman Witkin & 96 & 94 & 98 & 98 \\
\hline Mary Ainsworth & 97 & 42 & 58 & 56 \\
\hline Hobart Mowrer & 98 & 99 & 99 & 99 \\
\hline Anna Freud & 99 & 29 & 20 & 22 \\
\hline
\end{tabular}

${ }^{1}$ Haggbloom et al.'s [1] rank-ordered list of the 100 most eminent psychologists of the 20th century.

${ }^{2}$ Replicated SECEs-based rank-ordered list (averaged across three search engines) based on query of scientists' first name and surname (e.g., Albert Bandura).

${ }^{3}$ Replicated SECEs-based rank-ordered list (averaged across three search engines) based on query of scientists' first name and surname and the word "psychology" (e.g., Albert

Bandura psychology).

${ }^{4}$ Replicated SECEs-based rank-ordered list (averaged across three search engines) based on query of scientists' first name and surname and the word "psychologist" (e.g., Albert

Bandura psychologist). 


\section{REFERENCES}

[1] Haggbloom SJ, Warnick R, Warnick JE, et al. The 100 most eminent psychologists of the 20th century. Rev Gen Psychol 2002; 6: $139-52$.

[2] Shohat M, Musch J. Online auctions as a research tool: a field experiment on ethnic discrimination. Swiss J Psychol 2003; 62: 139-45.

[3] Tumasjan A, Sprenger TO, Sandner PG, Welpe IM. Election forecasts with Twitter: How 140 characters reflect the political landscape. Soc Sci Comput Rev 2010; http://ssc.sagepub.com/content/ early/2010/09/24/0894439310386557.abstract

[4] Vazire S, Gosling SD. E-Perceptions: personality impressions based on personal websites. J Pers Soc Psychol 2004; 87: 123-32.

[5] Rentfrow PJ, Gosling SD. The do re mi's of everyday life: the structure and personality correlates of music preferences. J Pers Soc Psychol 2003; 84: 1236-56.

[6] Norenzayan A, Atran S, Faulkner J, Schaller M. Memory and mystery: The cultural selection of minimally counterintuitive narratives. Cog Sci 2006; 30: 531-53.

[7] Bardi A, Calogero RM, Mullen B. A new archival approach to the study of values and value-Behavior relations: Validation of the value lexicon. J Appl Psychol 2008; 93: 483-97.

[8] Back MD, Stopfer JM, Vazire S, et al. Facebook profiles reflect actual personality, not self-idealization. Psychol Sci 2010; 21:372-4

[9] Ogan CL, Ozakca M, Groshek J. Embedding the Internet in the lives of college students. Soc Sci Comp Rev 2008; 26: 170-7.

[10] Bauer K, Bakkalbasi N. An examination of citation counts in a new scholarly communication environment. DLibMagazine 2005; 11. http://www.dlib.org/dlib/september05/bauer/09bauer.html

[11] Björneborn L, Ingwersen P. Toward a basic framework for webometrics. J Am Soc Inf Sci Tec 2004; 55:1216-27.

[12] Chen P, Xie H, Maslov S, Redner S. Finding scientific gems with Google's PageRank algorithm. J Informetr 2007; 1: 8-15.

[13] Kousha K, Thelwall M. Google Scholar citations and Google Web/URL citations: A multi-discipline exploratory analysis. J Am Soc Inf Sci Tech 2007; 58: 1055-65.

[14] Maslov S, Redner S. Promise and pitfalls of extending Google's PageRank algorithm to citation networks. J Neurosci 2008; 28: 11103-5.

[15] Mayr P, Tosques F. Google Web APIs-An Instrument for Webometric Analyses? Arxiv preprint 2005. Available at http:// arxiv.org/abs/cs/0601103

[16] Thelwall M. Bibliometrics to webometrics. J Inf Sci 2008; 34: 605-21.

[17] Vaughan L, Shaw D. A new look at evidence of scholarly citation in citation indexes and from web sources. Scientometrics 2008; 74: 317-30.
[18] Bar-Ilan J, Peritz BC. Informetric theories and methods for exploring the Internet: An analytical survey of recent research literature. Lib Trends 2002; 50: 371-92.

[19] Wilkinson D, Thelwall M, Li X. Exploiting hyperlinks to study academic web use. Soc Sci Comp Rev 2003; 21: 340-351.

[20] Wouters P, Scharnhorst A. Web indicators: a new generation of S\&T indicators? Cybermetrics 2006; 10. Available at http://www. cindoc.csic.es/cybermetrics/articles/v10i1p6.html

[21] Bagrow JP. On the Google-fame of scientists and other populations. Arxiv preprint 2005. Available at http://arxiv.org/abs/ physics/0504034

[22] Schmidt WC. Technical considerations when implementing online research. In: Joinson AN, McKenna KYA, Postmes T, Reips UD, Eds. The Oxford handbook of internet psychology (Oxford, 2007), Oxford: Oxford University Press 2007; pp. 461-72.

[23] Birnbaum MH. Human research and data collection via the internet. Annu Rev Psychol 2004; 55: 803-32.

[24] Reips UD. How Internet-mediated research changes science. In Barak, A, Ed., Psychological aspects of cyberspace: Theory, research, applications (Cambridge, 2007), Cambridge: Cambridge University Press 2008; pp. 268-94.

[25] Janetzko D. Objectivity, reliability, and validity of search engine count estimates. Int J Internet Sci 2008; 3: 7-33.

[26] Simonton DK. Leaders of American psychology, 1879-1967: career development, creative output, and professional achievement. J Pers Soc Psychol 1992; 62: 5-17

[27] UNESCO. World social science report 2010. Available at http:/ www.unesco.org/new/en/social-and-humansciences/resources/reports/world-social-science-report/

[28] Ammon U. To what extent is German an international language? In: Stevenson A, Ed. The German language and the real world (Oxford, 1995), Oxford: Oxford University Press 1995; pp. 25-53.

[29] Internet world stats 2011. Available at http://www.internetworldstats. com/stats $7 . h$ tm

[30] Conover WJ, Iman RL. Rank transformations as a bridge between parametric and nonparametric statistics. Am Stat 1981; 35: 124-9.

[31] Cohen J. Statistical power analysis for the behavioral sciences. Mahwah, NJ: Lawrence Erlbaum 1988.

[32] Stapp J, Fulcher, R. The employment of APA members. Am Psychol 1981; 36: 1263-314.

[33] Tumasjan A, Männich M, Spörrle M. The 100 most eminent psychologists of the 20th century on the internet: Do internet page counts provide latent indicators of scientific eminence? [Abstract] Int J Psychol 2008; 43: 122.

(C) Spörrle and Tumasjan; Licensee Bentham Open.

This is an open access article licensed under the terms of the Creative Commons Attribution Non-Commercial License (http://creativecommons.org/licenses/by-nc/3.0/) which permits unrestricted, non-commercial use, distribution and reproduction in any medium, provided the work is properly cited. 